\title{
Literatur
}

1. Reich, H., D. H. Nelson und A. Zaffaroni, J. biol. Chemistry 187, 411 (1950). - 2. Reich, H., K. F. Crane und S. F. SaNFIrIPPO, J. org. Chem. 18, 822 (1953). - 3. REICH, H. und B. K. SAMuels, J. org. Chemistry 19, 1041 (1954). - 4. Neher, R., J.
Chromatogr. (Amsterdam) 1, 122 u. 205 (1958). - 5. Kochakian, C. D. und G. Strdworthy, J. biol. Chemistry 199, 607 (1952). 6. Stupnicki, R. und E. StupNICKA, Nature 200, 165 (1963).

\section{Glutaminbestimmung in Serum und Liquor cerebrospinalis mit Glutaminase}

\author{
Von H. Kluge, H. Hermann und V. Wieczorek \\ Aus der Klinik für Psychiatrie und Neurologie „Hans Berger“ der Friedrich-Schiller-Universität Jena \\ (Direktor: Prof. Dr.v. Keyserlingk) \\ (Eingegangen am 4. Juli 1966)
}

\begin{abstract}
Es wird eine Methode zur Glutaminbestimmung in Sera und Liquores beschrieben. Sie basiert auf der Glutaminspaltung durch Glutaminase und anschließender Ammoniakbestimmung mit Phenol-Hypochlorit-Reagenz. Die Gewinnung der Glutaminase erfolgte auf einfachem Wege aus Schweinenierenmitochondrien. Die Fermentpräparate waren frei von ammoniak-abspaltenden Enzymen. Durch entsprechende Variation der Reaktionsbedingungen können 0,8-20 $\mu \mathrm{g}$ Glutamin pro Testansatz bestimmt werden.

A method is described for the determination of glutamine in serum and cerebrospinal fluid. It is based on the hydrolysis of glutamine with glutaminase, followed by the determination of ammonia with phenol-hypochlorite reagent. Glutaminase is obtained by a simple method from pig liver mitochondria; the enzyme preparations were free from other enzymes that release ammonia. By appropriate variations of the reaction conditions, it is possible to measure $0.8-20 \mu \mathrm{g}$ of glutamine per sample.
\end{abstract}

Die zahlreichen Funktionen des Glutamins im Stoffwechsel zeigen dessen große Bedeutung und bedingen gleichzeitig das ständig steigende klinische Interesse. Vor unseren Untersuchungen über den Glutaminstoffwechsel war zunächst die Ausarbeitung einer brauchbaren schnellen und vor allem spezifischen Methode zur Glutaminbestimmung erforderlich.

Die bisher beschriebenen Analysenverfahren benutzen die chromatographische Auftrennung, den chemischen Nachweis und die quantitative chemische oder enzymatische Bestimmung der Glutaminspaltprodukte nach enzymatischer Einwirkung. So ermittelte GEROK (1) den Glutamingehalt des Serums neben anderen Aminosäuren nach Elutionschromatographie an Ionenaustauschern. Ebenfalls mit Austauschchromatographie arbeiteten KNAUfF und Mitarbeiter (2). WAELSCH und Mitarbeiter (3-6) trennten das Glutamin aus Aminosäuregemischen an Dowex-Säulen ab. Die Austauschchromatographie hat den Nachteil, daß Asparagin nicht von Glutamin zu trennen ist und außerdem Serin interferiert (2). Weiterhin ist das Verfahren sehr zeitaufwendig und mit erheblichen Glutaminverlusten verbunden.

Neben der Austauschchromatographie wurden auch papierchromatographische Verfahren verwendet. KNAUfF und Mitarbeiter (7) beschreiben die Bestimmung des Glutamins auf diese Weise neben 20 weiteren Plasmaaminosäuren. Die Autoren geben gleichzeitig eine erschöpfende Literaturübersicht. Die Papierchromatographie ist aber ebenso zeitaufwendig und setzt wie alle bisherigen chromatographischen Verfahren eine Enteiweißung des Untersuchungsgutes voraus. Dadurch wird das Glutamin über eine erhebliche Zeit stark sauren Bedingungen ausgesetzt, die sicher Verluste bedingen. Den chromatographischen Verfahren dürfte die Be- stimmung der Spaltprodukte des Glutamins nach dessen enzymatischer Spaltung eindeutig überlegen sein. So nutzten Naijar und Fischer (8) den Decarboxylasegehalt des Acetontrockenpulvers von Escherichia coli aus, um nach enzymatischer Decarboxylierung einer Reihe von Aminosäuren aus einem Gemisch das Glutamin durch Differenzbildung zu bestimmen.

Waren die letzten beiden Methoden nur indirekte, so bedienten sich MEISTER und Mitarbeiter $(9,10,11)$, Tower und Mitarbeiter $(12,13)$, Conway (14), Krebs (15) sowie ZyDowo (16) direkter Verfahren. Tower beschreibt die Glutaminbestimmung mit Glutaminasehaltigen Extrakten aus Clostridium perfringens (welcbii). Das Enzym spaltet Glutamin in Glutaminsäure und Ammoniak. Beide Spaltprodukte können leicht quantitativ bestimmt werden. Zur Glưtaminsäurebestimmung wird neben der enzymatischen Methode hauptsächlich das Hydroxamsäureverfahren herangezogen $(17,18)$.

In dieser Arbeit wird ebenfalls eine enzymatische Methode beschrieben. Wir präparierten auf einfache Weise in Anlehnung an die Methoden von KuINGman und Handere (19) und SAYre und Roberts (20) eine genügend aktive und von Fremdaktivitäten freie Glutaminase. Das freigesetzte Ammoniak wurde mit einer etwas modifizierten Technik in Anlehnung an das Verfahren von BERTHELOT (21) bestimmt.

\section{Methodik}

Glutaminasepräparation

Frische Schweineniere wurde bei $0^{\circ}$ im Fleischwolf zerkleinert und mit 5 Volumenteilen $0,25 \mathrm{M}$ Rohrzuckerlösung $(0,02 \mathrm{M}$ an Boratpuffer; $\mathrm{pH} 8,1$ ) im „Starmix" homogenisiert. Die Homogenisierung erfolgte bei $0^{\circ}$ während $15 \mathrm{Min}$. mit mehreren Abkühlungspausen. Das Homogenat wurde $10 \mathrm{Min}$. bei $3000-3500 \mathrm{~g}$ zentrifugiert und das Sediment verworfen. Es enthält Bindegewebsreste, Zellkerne 
und einen Teil der schweren Mitochondrien. Der Uberstand wurde 25 Min. bei $20000 \mathrm{~g}$ zentrifugiert (Kühlzentrifuge). Das anfallende Sediment besteht haupsächlich aus Mitochondrien, welche die Glutaminase enthalten. Es wurde lyophilisiert und anschließend in $50 \mathrm{~g}$-Portionen mit $100 \mathrm{~m} /$ frisch destilliertem n-Butanol 30 Sek. bei $0^{\circ}$ homogenisiert. Die erhaltenen Suspensionen wurden rasch in je $500 \mathrm{~m} l$ auf $-5^{\circ}$ abgekühltes n-Butanol gegossen und weitere 3 Min. gerührt; danach wurde abgesaugt (Büchnertrichter). Der Rückstand wurde in $100 \mathrm{ml}$ auf $-5^{\circ}$ vorgekühltem Accton aufgewirbelt, wiederum scharf abgesaugt und mit je $500 \mathrm{ml}$ Aceton nachgewaschen. Zum Schluß wurden noch je $100 \mathrm{ml}$ Ather nachgesaugt. Das erhaltene Trockenpulver wurde im Vakuum bei $0^{\circ}$ getrocknet und in $5 \mathrm{~g}$-Portionen in Ampullen eingeschmolzen. Die Aufbewahrung erfolgte bei $-20^{\circ}$.

$5 \mathrm{~g}$ Trockenpulver wurden bei $0^{\circ} \mathrm{mit} .120 \mathrm{ml} 0,1 \mathrm{M}$ Phosphatpuffer pH 8,1, 60 Min. unter ständigem Rühren extrahiert. Die erhaltene Suspension wurde $30 \mathrm{Min}$. bei $20000_{\mathrm{g}}$ zentrifugiert, das Sediment verworfen und der Uberstand auf Zimmertemperatur gebracht. Nach Einrühren von fein pulverisiertem Natrium bis $0,5 \mathrm{M}$ Endkonzentration wurde $30 \mathrm{Min}$. bei $80000 \mathrm{~g}$ (oder $90 \mathrm{Min}$. bei $20000 \mathrm{~g}$ ) zentrifugiert, das Sediment verworfen und der Überstand bis zu einer Endkonzentration von $1,0 \mathrm{M}$ an Natriumsulfat gebracht (Zimmertemperaturl). Nach 10 Min. wurde 15 Min. bei $20000 \mathrm{~g}$ und Zimmertemperatur abzentrifugiert. Das Sediment enthielt die Glutaminaseaktivität und wurde - in 0,1 M Phosphatpuffer $\mathrm{pH} 8,1$ aufgenommen - portionsweise bei $-20^{\circ}$ aufbewahrt.

Aktivitätstest der Glutaminasepräparation

Die Bestimmung der Enzymaktivität erfolgte nach PiNrrLIE und Mitarbeiter (22).

Der Eiweißgehalt wurde nach der modifizierten Biuretmethode bestimmt (23).

Die Glutaminasepräparationen wurden auf folgende Fremdaktivitäten untersucht: Asparaginase, Arginase, Histidase, Histaminase und Urease. Dabei wurde statt Glutamin im ansonsten gleichen Inkubationsansatz das entsprechende Substrat eingesetzt.

Inkubationsansatz für die Glutaminspaltung

In Blind- und Hauptwerte pipettiert man je $0,2 \mathrm{~m} l$ Phosphatpuffer $0,1 \mathrm{M} \mathrm{pH} 8,1$ und $0,02 \mathrm{ml}$ Glutaminasepräparation $(150-170 \mu \mathrm{g}$ Protein enthaltend). In die Hauptwerte werden dann $0,04 \mathrm{~m} /$ Serum bzw. Liquor gegeben und alle Ansätze 15-25 Min. bei $37^{\circ}$ inkubiert. Die Weiterbehandlung erfolgt wie im nächsten Abschnitt angegeben.

\section{Ammoniak-Bestimmung}

\section{Reagenzien}

Lösung I: $5 \mathrm{~g}$ Phenol und $7 \mathrm{mg}$ Nitroprussid-Na auf $100 \mathrm{ml}$ dest. Wasser.

Lösung II (2,5-proz. an $\mathrm{NaOH}$ und 0,025-proz. an Hypochlorit): Natronlauge und Hypochloritlösung sind als 5 bzw. 0,05-proz. Lösungen getrennt herzustellen und vor Gebrauch zu mischen. Nesler-Reagenz: 1:20-Verdünnung des nach VANSELOw (24) hergestellten Reagenzes.

Gesättigte Kaliumkarbonatlösung.

$\mathrm{NH}_{3}$-Standard: 47,2 mg Ammoniumsulfat werden auf $1000 \mathrm{ml}$ aufgefüllt $(10 \mu \mathrm{g} \mathrm{NH} / 3-\mathrm{N} / \mathrm{ml})$.

10-proz. Trichloressigsäure

\section{Bestimmung nach BERTHELOT (modifiziert)}

Die Inkubationsansätze für Liqụor (Haupt- und Blindwerte) versetzt man nach abgeschlosssener Inkubation direkt mit $0,25 \mathrm{~m} /$ eiskalter Lösung I. Danach werden in die Blindwerte $0,02-0,04 \mathrm{~m} l$ Liquor und in Blind- und Hauptwerte $0,25 \mathrm{~m} l$ Lösung II pipettiert. Nach gründlichem Schütteln werden alle Ansätze 15 Min. bei $37^{\circ}$ inkubiert, schnell abgekühlt und mit $2 \mathrm{~m} l$ dest. Wasser versetzt. Wiederum schüttelt man gut durch und mißt nach 10 Min. bei 620-640 $\mathrm{m} \mu$ und $1 \mathrm{~cm}$ Schichtdicke Haupt- gegen Blindwerte. Die Inkubationsansätze für Serum können prinzipiell in gleicher Weise aufgearbeitet werden. Es empfiehlt sich aber, eine Enteiweißung durchzuführen, da sonst die Blindwertextinktionen zu hoch liegen. Nach der Inkubation ist daher wie folgt zu verfahren: Alle Ansätze werden auf $0,4 \mathrm{ml}$ Endvolumen mit aqua dest. ge- bracht und $0,1 \mathrm{~m} l 10$-proz. Trichloressigsäure zugegeben. In die Blindwerte setzt man jetzt $0,04 \mathrm{~m} l$ Serum nach, schüttelt alle Ansätze gut durch und zentrifugiert kurzzeitig scharf ab. Von den Uberständen werden $0,4 \mathrm{ml}$ entnommen, $0,4 \mathrm{ml}$ Lösung I und $0,4 \mathrm{~m} l$ Lösung II nacheinander zugesetzt und alle Ansätze $15 \mathrm{Min}$. bei $37^{\circ}$ inkubiert. Nach raschem Abkühlen werden in alle Ansätze $3 \mathrm{~m} /$ aqua dest. pipettiert und nach $10 \mathrm{Min}$. Haupt- und Blindwerte gemessen (s. oben).

Bestimmung nacls RICHTERICF und COLOMBO (25)

Die Inkubation zur Glutaminspaltung wird im 10-fachen Ansatz wie oben beschrieben, durchgeführt und direkt in Mikrodiffusionsflaschen angesetzt. Die weitcren Arbcitsgänge entsprechen den in (25) angegebenen.

\section{Ergebnisse und Diskussion}

Bisher wurden drei Glutaminase-Chargen präpariert, deren spezifische Aktivitäten zwischen 230 und 270 IE lagen (IE $=\mu \mathrm{Mol}$ freigesetztes $\mathrm{NH}_{3}$ pro Minute und $\mathrm{g}$ Protein). Bei einem Glutamingehalt von $10 \mathrm{mg} \%$ wären im verwendeten Serum- bzw. Liquoransatz (s. Methodik) $4 \mu \mathrm{g}$, also etwa $3 \times 10^{-2} \mu \mathrm{Mol}$ Glutamin gespalten. Nach den gefundenen spezifischen Aktivitäten würden für einen vollständigen Umsatz dieser Glutaminmenge in $20 \mathrm{Min}$. etwa $10 \mu \mathrm{g}$ Enzymprotein benötigt. Diese Menge wäre sicherlich aus kinetischen Gründen limitierend, so daß ein 5-, 10- und 20-facher Enzymüberschuß zum vollständigen Umsatz verwendet und die Reaktion gleichzeitig auf Zeitabhängigkeit geprüft wurde (Tab. 1). Aus Tabelle 1 geht hervor, daß mit

Tab. 1

Umsatzraten von Glutamin (2,12 $\mu \mathrm{g}$ pro Ansatz) in Abhängigkeit von der Enzymproteinmenge.

Bedingungen wie Ansatz für Liquor (s. Methodik). Angaben als Extinktionen bei $620 \mathrm{~m} \mu$ und $1 \mathrm{~cm}$ Schichtdicke

\begin{tabular}{cccc}
\hline $\begin{array}{c}\text { Proteineinsatz } \\
(\mathrm{mg})\end{array}$ & \multicolumn{2}{c}{$\begin{array}{c}\text { Extinktion nach } \\
15\end{array}$} & $\begin{array}{c}\text { Reaktionszeit } \\
\text { Min.) }\end{array}$ \\
\hline 0,042 & 0,043 & 0,070 & 0,076 \\
0,085 & 0,089 & 0,089 & 0,084 \\
0,170 & 0,086 & 0,087 & 0,085 \\
\hline
\end{tabular}

einem 10-fachen Enzymüberschuß die eingesetzte Glutaminmenge bereits nach $15 \mathrm{Min}$. gespalten ist. Die 5-fache Menge ist selbst für eine halbstündige Inkubationszeit nicht ausreichend. Für den Fall erhöhter Glutamingehalte wurde deshalb generell der 10-fache Enzymproteinüberschuß bei 20-25 Min. Reaktionsdauer verwendet (s. Methodik). Während dieser Zeitspanne ist der Eigenzerfall des Glutamins, der Sera und der Liquores ohne Einfluß (Tab. 2). Alle verwendeten

Tab. 2

Eigenzerfall von Glutamin $(3 \mu \mathrm{g})$, Serum $(0,04 \mathrm{ml})$ und Liquor $(0,04 \mathrm{ml})$ während $45 \mathrm{Min}$. und $37^{\circ} \mathrm{im}$ Inkubationsgemisch ohne Enzymzusatz. Angaben als Extinktionen bei $620 \mathrm{~m} \mu$ und $1 \mathrm{~cm}$ Schichtdicke

\begin{tabular}{cccc}
\hline $\begin{array}{c}\text { Reaktionszeit } \\
\text { (Min.) }\end{array}$ & Glutamin & $\begin{array}{c}\text { Extinktion für } \\
\text { Serum }\end{array}$ & Liquor \\
\hline 0 & 0,002 & 0,207 & 0,009 \\
45 & 0,003 & 0,215 & 0,007 \\
\hline
\end{tabular}

Glutaminasepräparationen waren frei von Urease-, Histidase-, Histaminase-, Arginase- und Asparaginaseaktivität.

Die Zuverlässigkeit der Methode, den Erfassungsbereich und die geringe Streuung der Einzelwerte zeigen die 
Klein 1981, Rietema 1982). Macrothalli were encountered from March to September on the Murman coast (Fig. 9A). For the rest of the year it persisted as small crusts (microthallus stage). Macrothallus development began in March at low temperatures ( -0.5 to $0^{\circ} \mathrm{C}$ ), when daylength exceeded $10-13 \mathrm{~h}$. The maximum size was reached in July (length) and in July-August (weight). Estimates of relative growth rate suggested maximal growth in March-April in the second year, and in May-June in the first year (Fig. 9B, Table I).

Fertile plants were observed from late June through September (Fig. 9C). The formation of reproductive organs commenced during the polar day (late June) at temperatures near $5^{\circ} \mathrm{C}$. The tetra- and carpospores were released primarily in August. In September, decaying plants with some unshed tetraspores were found. The tetrasporophytes, comprising
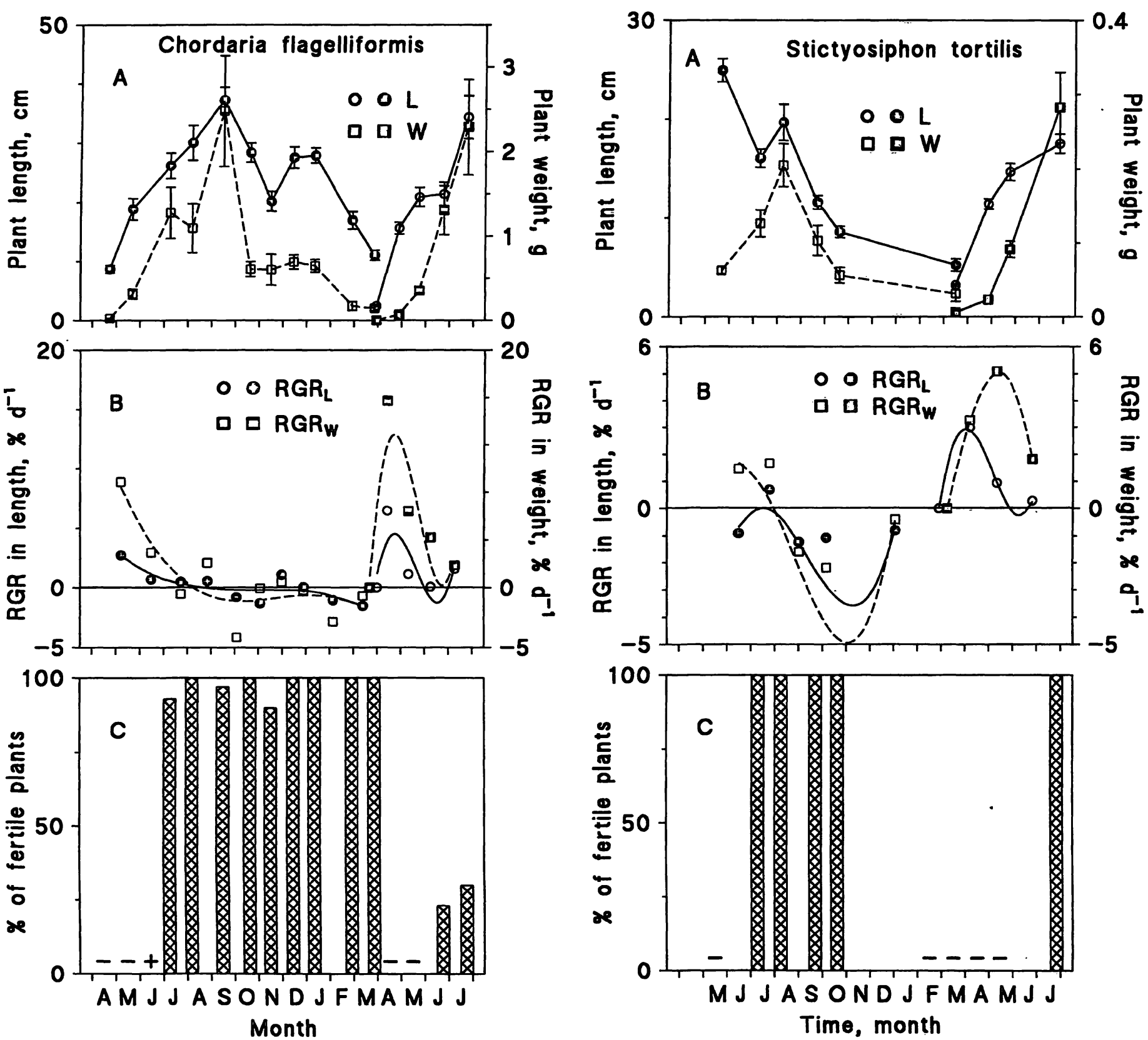

Fig. 7. Chordaria flagelliformis. (A) Mean length (L) and weight (W) ( \pm SE) of plants. (B) Relative growth rates in length $\left(R G R_{L}\right)$ and in weight $\left(R G R_{W}\right)$ derived from length and weight measurements. Open or dark keys - first or second year generations. (C) Percentages of fertile plants. '-' only sterile plants occurred, '+' fertile plants were observed, but not quantitatively collected (Dalnezelenetskaya Inlet, Barents Sea, April 1993-July 1994, $\mathrm{n}=30$ plants in every sample).

Fig. 8. Stictyosiphon tortilis. (A) Mean length (L) and weight (W) ( \pm SE) of plants. (B) Relative growth rates in length $\left(R G R_{L}\right)$ and in weight $\left(R G R_{W}\right)$ derived from length and weight measurements. Open or dark keys - first or second year generations. (C) Percentages of fertile plants. '-' only sterile plants occurred (Dalnezelenetskaya Inlet, Barents Sea, May 1993-July 1994, $\mathrm{n}=30$ plants in every sample). 